\title{
Decision Support System Using Mobile Applications in the Provision of Day to Day Information about Farm Status to Improve Crop Yield
}

\author{
Erastus O. Ogunti ${ }^{1}$, Francis K. Akingbade ${ }^{1}$, Adebayo Segun ${ }^{2}$, Oloyede Oladimeji ${ }^{3}$ \\ ${ }^{1}$ Department of Electrical and Electronics Engineering, Federal University of Technology, Akure, Ondo State Nigeria \\ ${ }^{2}$ Department of Computer Science and Information Technology, Bowen University, Iwo, Osun State Nigeria \\ ${ }^{3}$ Directorate of Information and Communication Technology, Bowen University, Iwo, Osun State Nigeria
}

\section{Article Info}

Article history:

Received Aug 24, 2018

Revised Oct 16, 2018

Accepted Oct 26, 2018

\section{Keyword:}

Smart Farming,

Mobile App,

Decision Support System

\begin{abstract}
Agricultural sector is a viable option in the diversification of Nigeria's economy due to its large contribution of over $40 \%$ of the Gross Domestic Product (GDP) and it employment of about $60 \%$ of the working population. The sector is current faced with a decline in youth participation in Agriculture as well as poor crop yield of 1.8tons per hectare when compared to other country such as Egypt with 9.64 tons per hectare. The study identifies the use of information technology as a solution to these problems based on the large success rate in social media amongst youth population of the country. The study review various information technology farming tools which are capable of improving crop yield and increasing youth interest is agriculture. Finally, the study described the process of developing a rice farm decision support system to help rice farmers improve their yield.
\end{abstract}

\section{Corresponding Author:}

Adebayo Segun,

Department of Computer Science and Information Technology,

Bowen University, Iwo,

Osun State Nigeria

E-mail: shegdabayo@yahoo.com

\section{Introduction}

Farming refers to an agricultural process such as growing crop or keeping animals for food or raw materials. It typically entails day-to-day activity on the field. For instance, in growing crop, decision such as seed sowing, weeding, fertilizing, and other related agricultural task had to be made for optimum yield of the crop. Such decision making at the right time, in the right place, with the right amount or quantity of inputs need accurate information so as to improve yield, reduce waste, save effort and ultimately increase productivity.

Information is an entity that provides the answer to a question of some kind or resolves uncertainty. It is thus related to data and knowledge, as data represents values attributed to parameters, and knowledge signifies understanding of real things or abstract concepts [1]. Information on the day-to-day factors influencing crop growth has been important for farmers for ages and in the past, farmers had mainly used direct human observations to recognize these factors. This method of monitoring factors affecting crop growth has its challenges ranging from prompt decision making that will greatly affect crop yield and productivity. This fact has been responsible for the subsistence nature of farming in Africa and in Nigeria in particular.

A study by [2] shows that information is a key factor in making effective decisions in all industrial sectors including agricultural sector. It recognized that information can help farmers increase agricultural productivity. By providing up-to-date information about prices as well as market demands, farmers are able to choose the type and amount of crops to grow, and where to sell these products, to maximize profits. It further states that prompt crop disease warnings and predictions allow farmers to take actions to minimize damage, update farming knowledge as well as educate farmers of new ways to improve their crop yields. Although information may be available, some farmers especially small-scale farmers, are not able to meet the expected yield quality, supply, and demand at the market level due to the lack of information visibility at the time of 
decision making. Study by [3] shows that the fact that farmers are not able to make optimal decisions at different stages of the farming life cycle results in a huge impact on farmers' revenue. Thus innovative information system for agriculture is an effective solution for this problem.

Information gathering using technology has been considered as an effective key tool to improving crop productivity through the measuring and reporting of factors responsible for the growth of crop to provide information on how, when and where to use farming inputs during farming cultivation in such a way to reduce wastage, provide all necessary requirements for the crop and enhance yield.

Smartphones is a technology that has gained popularity in the acquisition of information by humans in recent times. A study by an online retail shop Jumia [4] shows that the number of Nigeria's mobile subscribers has reached 150 million, and internet users has climbed to 97.2 million at penetration rates of $81 \%$ and $53 \%$, respectively. The study further shows that Africa has 960 million mobile subscribers and 216 million internet users at penetration rates of $80 \%$ and $18 \%$, respectively. Nigeria's growing mobile internet user base speaks to its market potential. Nigeria currently has 62.2 million and 52.1 million more internet and mobile users respectively than Egypt. It also outpaces Kenya by 65.3 million and 110.78 million internet and mobile users, respectively. The increased mobile internet appetite in Nigeria had been attributed to several factors such as:

- Access to better and cheaper smartphones. The average price of mobile phones on online retail shop such as Jumia dropped to $\$ 117$ from $\$ 216$ in 2014. Additionally, smartphone sales increased by $394 \%$ on Jumia from 2014-2016[4].

- Improved mobile network ecosystem. The Nigerian Communication Commission (NCC) efforts have already shown improvements in service in the first quarter of 2017.

- Access to "lite" mobile applications, which require less data. Customers in Nigeria have lower incomes and many of the mobile data packages offered are cost prohibitive. For example, Nigerian smartphone users tend to use Opera mini, a lite version of the Opera mobile browser, more often than they use Google Chrome, which is the most popular mobile browser globally. The availability of datasaving mobile services makes mobile usage more alluring to consumers.

Furthermore, considering data from the Central Intelligent Agency (CIA) World fact book which shows that $43 \%$ of the population of Nigeria is between the ages of 0-14 years, 19.6\% are between the ages of 15-24 years, $30.74 \%$ are between the ages of $25-54$ years, $3.97 \%$ are between the ages of 55-64 years while only about $3.13 \%$ of the population is over 65 years of age [5], this means that a higher number of smartphone and internet users in Nigeria are between 13 years of age and 50 years. Report of decline in youth participation in agriculture empowerment programs despite effort by the federal and state governments in Nigeria to adopt capacity building on agriculture in order to reduce youth unemployment, restiveness and re-awake agriculture potentials [6] can be overcome if agriculture can tap into smartphone, internet and social media penetration amongst the youth which forms the bulk of the Nigeria population. This serves as a motivation of this study to review various mobile application available to farmers and to present a mobile App design that will provide day to day information about farming activities for optimum decision making

\section{Importance of Agriculture to Nigeria's Economy}

In the past, agriculture was the major exchange earner for Nigeria before the discovery of crude oil. In the western part of the country cocoa was a major crop produced and exported, in the northern part, it was groundnut and cotton with several pyramids of groundnuts bag on display while in the eastern part of the country, palm oil and palm kernel were the major agricultural product. In recent time due to fall in the price of crude oil in the international market, which had negatively affected the country's economy, the country is looking at diversifying its economy from a sole crude oil based one to a multidimensional based one. Agricultural sector remains a viable option in this diversification. It remains the single largest contributor to the well-being of the rural poor with a contribution of over $40 \%$ of the Gross Domestic Product (GDP) and the employment of about $60 \%$ of the working population (Oyakhilomen and Zibah, 2014). Thus, for agriculture to remain a viable option, there is a need to improve the productivity of cultivated crop. This means the ratio of the crop harvested in a cultivated area to inputs used in the crop cultivation should be high. Maximizing inputs such as labour, land, fertilization, irrigation and so on will reduce cost, and ultimately improve yields. With the huge penetration of smartphones in Nigeria, the agricultural sector can capitalize on smartphone adoption to improve the yield of crops through the use of precision farming system.

The concept of precision farming is a form of a measuring system that provides information about the physical value of the cultivated crop for prompt decision making that will improve crop yield. A section of this precision farming is a decision support system using mobile application platform to provide information. 


\section{Agricultural Decision Support System Products}

According to Singhal, Verma [7], farmer's information needs can be categorized into three stages: the first stage is the know-how, which includes information about crop choices and seed varieties, the second stage is the context of planting, which is the information about weather, plant protection and cultivation practices and the third stage is knowledge of market information which refers to market prices, market demands and logistics to sell products. Many farmers have to worry themselves to obtain this information which is a huge burden coupled with the farming itself. Fortunately, recent advances in smartphone application development and an increasing availability of smartphones allow for some of these agricultural burdens to be lifted and guided. For example, farmers may calculate proper amounts of fertilizers for crop fields upon analyzing color of crop leaves with some help from smartphone applications [2]. Also up-to-date information about prices and market demand of specific crop or product helps farmers in choosing the type and amount of crop to grow as well as where to sell the product to maximize profits. This section reviews smartphone applications under farming category and how they may aid farmers to achieve farming tasks.

Decision Support Systems (DSS) for Agriculture are information technology (IT) resources that are designed to help farmers tackle complex problems in crop production, utilizing the best available data and knowledge about scientifically-sound best practices. These technological systems, support smart farming which can reduce labour and fertilizer inputs, minimize negative environmental impacts, and also increase yields. Agricultural decision support systems can incorporate inputs on climate, water, genetics, energy, landscape, human, and economic resources, and ideally provide an analysis of how these factors work together in influencing productivity. There are a number of systems on the market today. Although the current acceptance of such products among farmers is low, it is expected to change in the future especially in Nigeria. One of the indicators of this position was the Federal Government's earlier program to provide farmers with free phones to help in reducing the bottleneck usually associated with fertilizer distribution. As world population grows and the availability of arable land diminishes, there is an increasing need to make a smart use of each piece of land. Several Mobile applications had been developed by scientist to assist farmers in gathering information about their farm field. The aim of this study is to review these existing mobile applications with their various function. The study also presented a developed mobile application and compared it with the existing ones.

DSS developed by Trimble [8] known as Connected Farm Field App allows farmers to enter detailed field records about their farming operations using a smartphone or tablet. The app is flexible and can handle any crop type, such as corn, beans, wheat, and more. Costs can be entered for each input so that financial information can be captured about each farming event. The app can install to multiple devices so that field records can be collected instantly and sent to Connected Farm where profit/loss information can be viewed for the entire operation. It can run on Android, iPad and iPhone devices
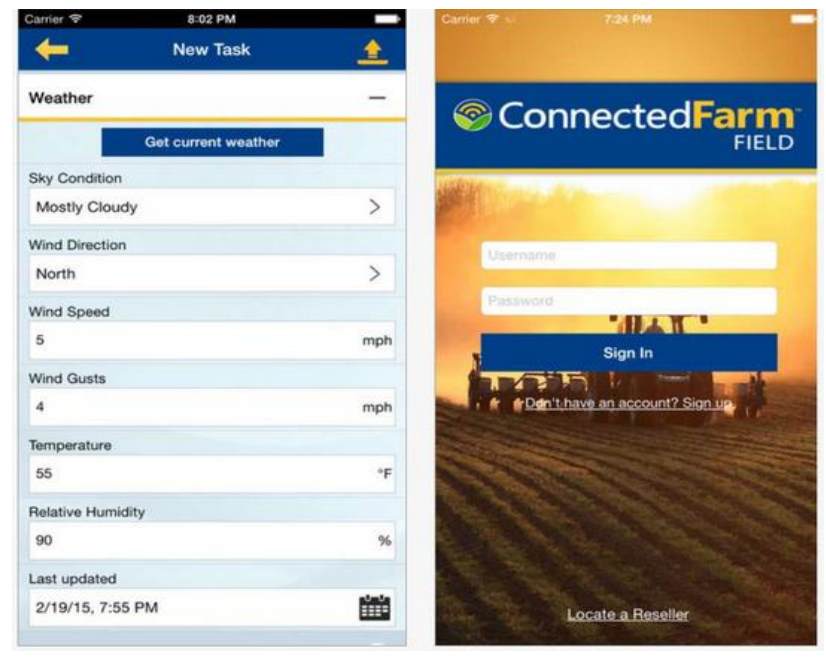

Figure 1 Connected Farm Field App

Oklahoma State University's App called Canopeo [9] allows users to quantify green vegetation in a plant's canopy in the field through photos taken using a smartphone. The app analyzes the images and provides an 
accurate measure of percent canopy cover for row crops, grassland, turf grass, or other green vegetation. The information can be used to monitor a crop's growth or evaluate damage and allows the user to adjust management decisions. It can run on Android, iPad and iPhone
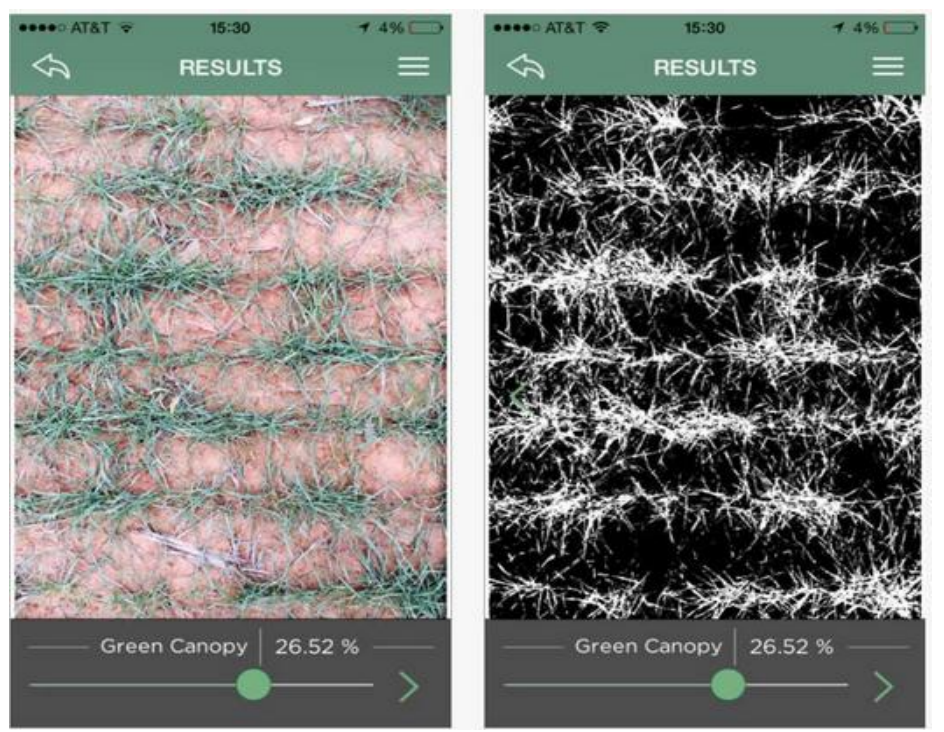

Figure 2 Canopeo App

Farm at Hand [10] is a free, cloud-based farm App that can be used to manage the entire farming operation from seed to sale, anytime, anywhere via your computer, tablet, or smartphone. Launched in 2012, the App keeps user organized, efficient, and productive all year long by capturing key field data. Track activities like planting, spraying, scouting, harvesting, and more. Automatically download reports for crop insurance, agronomists, and market consultants.

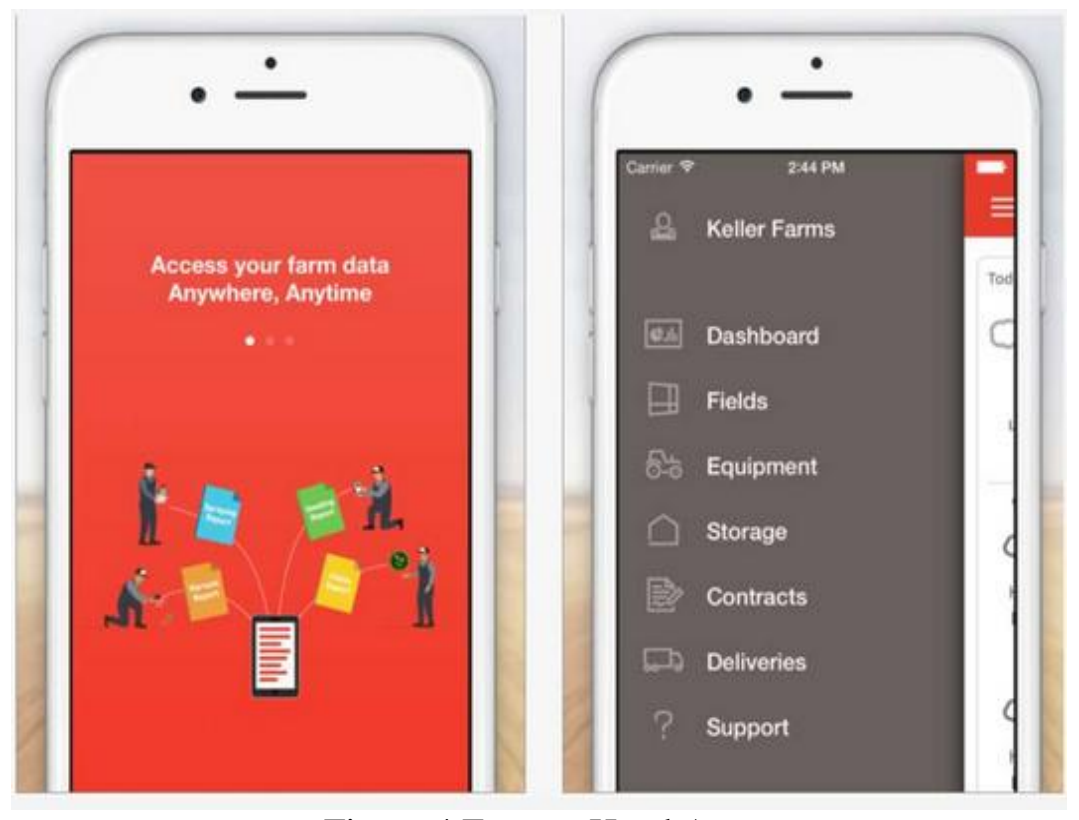

Figure 4 Farm at Hand App

PotashCorp-eKonomics program, an online agricultural resource dedicated to helping farmers maximize their yields and profits, has released an updated version of its valuable return-on-investment (ROI) calculator [11]. The latest calculator model incorporates spatial variability, giving farmers a more accurate reflection of expected nutrient response in production-sized agriculture. As a result, farmers are able to make more accurate nutrient application plans, maximizing the benefits of crop inputs and increasing their profitability. 


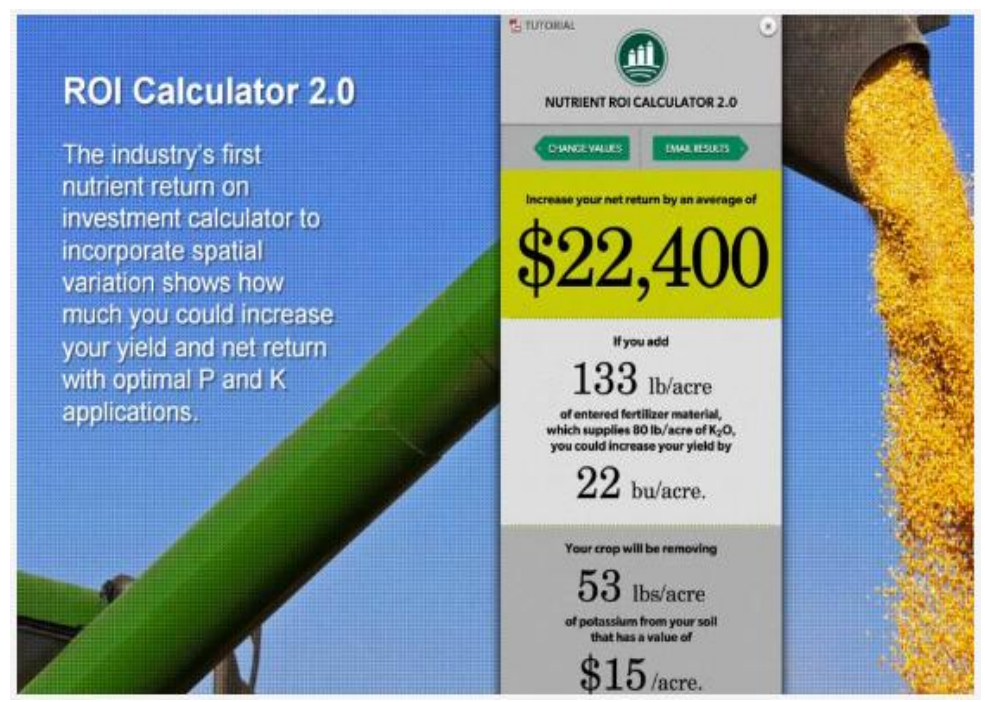

Figure 5 ROI Calculator

Yara ImageIT [12] is a farming App designed to measure nitrogen uptake in a crop and generate a nitrogen recommendation based on photographs of the crop. The App turns a farmer's smartphone camera into a hightech crop nutrient tester. ImageIT calculates nitrogen uptake based on leaf cover (leaf area index), leaf green colorv (green area index) and estimated fraction of brown leaves. The technology behind ImageIT is a comprehensive image analysis that classifies leaf pixels, filters noisy areas and counts leaf pixels. ImageIT is user-friendly and flexible in terms of technical requirements. ImageIT is largely insensitive to camera type and works with low resolution images with a file size as small as $50-200 \mathrm{~KB}$. In fields where there is poor network coverage ImageIT can save the photos on the smartphone so that the user can carry on taking photographs and then send them later for interpretation when reception is regained. Besides showing the user how much nitrogen to apply to obtain optimal yield and crop quality, ImageIT provides quality assured fertilizer recommendations with Yara preferred product and contact information of the closest Yara office.
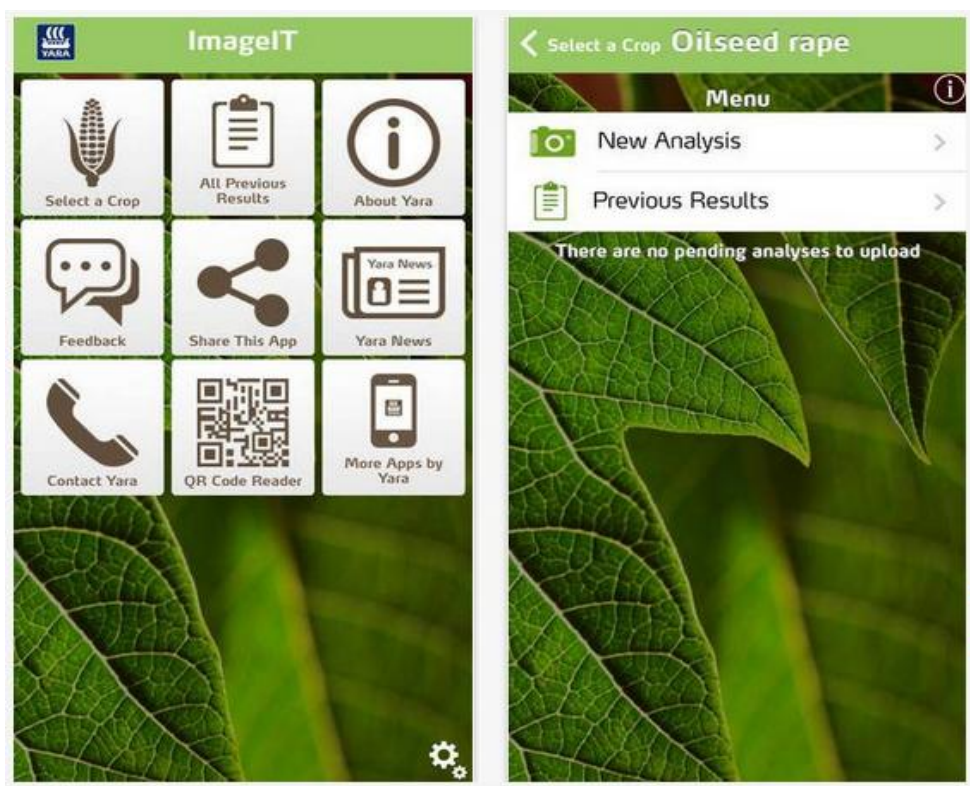

Figure 6. Yara ImageIT App

Pocket Rain Gauge App developed by Agrible [13] records rainfall measurements based on the location using GPS. User log in to morning farm report account to get total rainfall for all the fields tied to the account. Data on Agrible website is updated every hour and reflects the previous 24 hours. The App includes feedback functionality so that Agrible know how accurate its measurements are. 


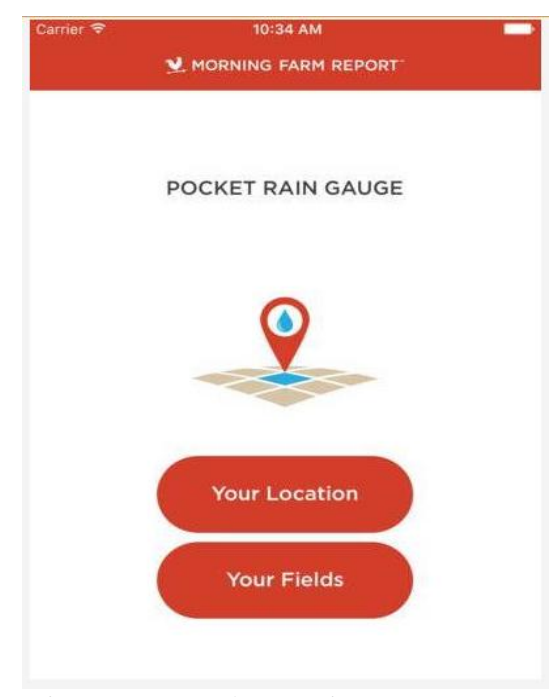

Figure 7. Pocket Rain Gauge App

AfricaRice [14] developed an android based decision support tool called RiceAdvice-Weed Manager to provide farmers with field-specific management guidelines for rice production systems in Africa. The App has two tools; RiceAdvice (target yield, nutrient management and crop calendar) and RiceAdvice-WeedManager. TheApp is supported in English, French and Kiswahili languages. The tools are interactive, and the guidelines provided by these tools are generated based on farmers' answers to multiple choice questions on farm conditions, crop management practices and market. Expected users include farmers, extension workers, private rice sectors, and development agencies in Africa who are interested in advice for rice. production. RiceAdvice tools can be used on Android devices (version 4.4 and up). Although they can be largely used without an internet connection, an active connection is required from time to time to synchronize information with the database server. Currently the app is available in Benin, Burkina Faso, Cameroon, Chad, Côte d'Ivoire, DR Congo, Egypt, Ethiopia, Ghana, Guinea, Madagascar, Mali, Mauritania, Niger, Nigeria, Rwanda, Senegal, Sierra Leone, Tanzania, The Gambia, Togo and Uganda.

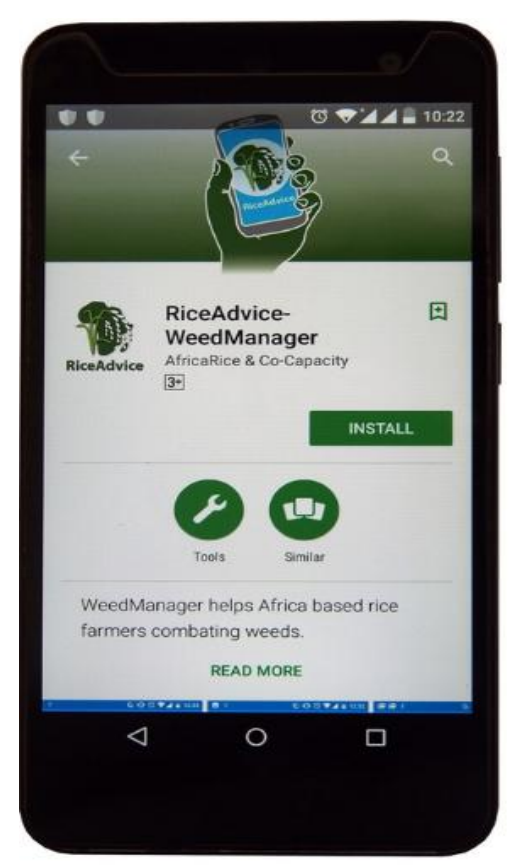

Figure 8 RiceAdvice-WeedManager App

In 2017, Farmcrowdy, a Nigerian digital agriculture platform develops an App for Android, iOS and Windows mobile devices. The idea is to make users participate in hassle-free farming from their mobile phone and make 
healthy returns while making a positive impact on the life of a rural farmer. The user can sponsor farms by identifying a farm choice and sponsor as many units as can be afforded by paying the required amount. Updates and progress reports are sent to the sponsors, and at the end of the farm cycle duration, the sponsors are paid the initial sponsorship and returns after harvest. Users can also follow farms when they can't sponsor a farm yet. The Follow Farm option allows the user to follow a farm of interests through farm updates and notifications. Finally, the learn option allows users to acquire requisite knowledge through updates, blog posts and other content that could help them get necessary information on the right steps and options available for in the agriculture space. Farms such as cassava farms, poultry farm, soya beans farm, Rice farm and Maize farm can be followed and sponsored.

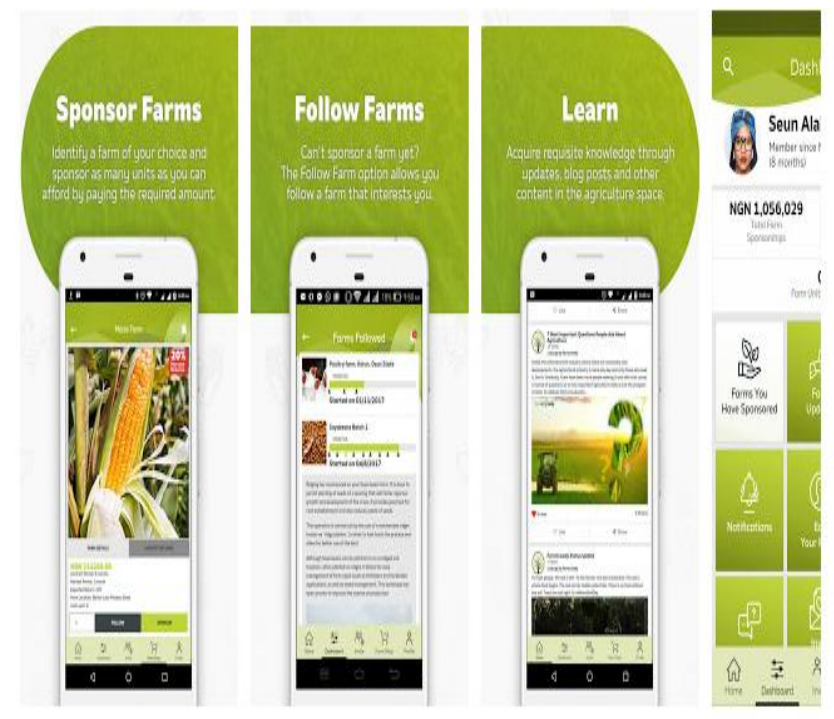

Figure 9 Farmcrowdy- FREE Digital Agriculture App

A study by [1] shows a method of creating Expert system for decision support on the Android platform. The system knowledge base for the given area of expertise was generated by inductive learning methods based on examples from the WEKA data research system. The system was realized using the Expert System shell for the e2gDroid lite mobile device, based on the application area and a set of training examples, specifically based on the Covertype DataSet qualification problem.

\section{Development of a Decision Support System App for Rice Farmers 4.1 Motivation for Development}

Rice is the most important food crop of the developing world and the stable food of more than half of the world's population [15]. Interestingly, research by the United State Department of Agriculture (USDA) shows that Nigeria is the Africa's largest rice consumer and 11th in the world. Unfortunately, available statistics by Food and Agricultural Organization of United Nation [16], shows that the production yield of rice in Nigeria is low compared to other countries. The gap between consumption and production is filled by importation putting a stress on the nations' trade balance. In recent time the government of Nigeria had banned the importation of Rice into the country putting a stress on the local farmers to produce more rice in order to feed the growing populace. Thus, the need to increase the yield of this food crop using several means.

\subsection{Decision Support System using Design of Experiment}

Decision support system is the combination of tools, data and techniques which is designed to help users to make decisions [17]. A DSS such as this will help farmers improve their yield. The first step in development of a DSS is feasibility study. This includes categorizing the various growth stages of rice plant, grouping these stages with various factors that affect the yield of this plant and obtaining the minimum need of this plant at each stage as shown in Table 1. The next step is system design and implementation.

To design the proposed DSS a design of experiment (DOE) methodology was adopted. DOE is a branch of applied statistics which uses mathematical methodology for planning and conducting experiments as well as 
analyzing and interpreting data obtained from the experiments. It is a branch of applied statistics that is used for conducting scientific studies of a system, process or product in which input variables (Xs) were manipulated to investigate its effects on measured response variable (Y) [18].

The process involves:

1. Stating the objectives: This is a list of problems that needs to be investigated for optimum design of a mobile App for farmers. In rice farming there are factors which affect the yield of rice, the question is to what extent does each of the identified factors affect rice yield.

2. Response variable definition: This is measurable outcome of the experiment that is based on defined objectives. In this scenario the response variable is yield.

3. Determining the factors and levels: This is the selection of independent variables or factors. Table 1 shows the factors as well as the minimum and maximum levels for optimum yield of the crop. Several studies, as shown in table 2, indicate that all factors have significant effect on the yield of the crop. Thus the consideration of these factors in the design of a mobile App to provide information on the status of rice farm will improve the yield of the crop.

$\begin{array}{clllll}\text { Table 1. Suitable Environmental Factors for Rice Growth } & & & & \\ \text { Growth Phases } & \text { Growth Stages } & \text { Temperature }\left({ }^{\circ} \mathrm{C}\right) & \text { Soil Moisture } & \text { Soil } \mathrm{pH} & \text { Pest Protection } \\ & & {[19]} & {[20]} & {[21]} & {[22]} \\ \text { Germination } & \text { Germination } & 18-40 & \text { Wet } & 6.5-7.0 & - \\ & \text { Seedling emergence } & 25-30 & \text { Wet } & 6.5-7.0 & - \\ & \text { Rooting } & 25-28 & \text { Wet } & 6.5-7.0 & - \\ & \text { Leaf elongation } & 31 & \text { Wet } & 6.5-7.0 & - \\ \text { Vegetative } & \text { Tillering } & 25-31 & \text { Wet } & 6.5-7.0 & \text { Needed } \\ \text { Reproductive } & \text { Initiation of panicle primordial } & 25-31 & \text { Wet } & 6.5-7.0 & \text { Needed } \\ & \text { Panicle differentiation } & 30-33 & \text { Wet } & 6.5-7.0 & \text { Needed } \\ \text { Ripening } & \text { Anthesis } & 30-33 & - & - & \text { Needed } \\ & \text { Ripening } & 19-20 & - & - & \text { Needed }\end{array}$

\subsection{Implementation Tools}

The implementation of the mobile application was done using android studios. Android was chosen as a platform for the implementation due to its availability and number of users. According to the statistics available on google, over 35 million android users are available in Nigeria alone. The android studio is powered majorly by java for the logic part and $\mathrm{xml}$ for the frontend.

Different libraries were integrated with the android studios which include android volley for making http calls. In other for the system to function effectively, the mobile application makes the necessary API calls to the data source which is the cloud. The cloud has a restful service which has been designed to handle different form of http calls including POST and GET.

A simple algorithm resides on the mobile application which makes a judgment based on the data received. Analysis are performed on the data received and the farmer is advised based on the output of the algorithm. The frontend of the mobile application is the part of the mobile application which the user relates with the mobile application. XML is used as a language for this due to its compatibility with other technologies. Elements on the mobile application are assign properties based on a preset design. It is worth to note that the usability of a mobile application depends on versatility of the mobile application.

\subsection{Result}

Figure 10 shows the Farm Report menu page of the mobile App. Measured values of crop stage, atmospheric temperature, soil moisture, and soil $\mathrm{pH}$ are retrieved from the cloud when the mobile phone is connected to the internet. The mobile app performs logic evaluation using the measured values to display a decision in form of an advice for the farmer to take decisive action. Figure 11 shows the icon of the developed android mobile App deployed on a real mobile phone. 


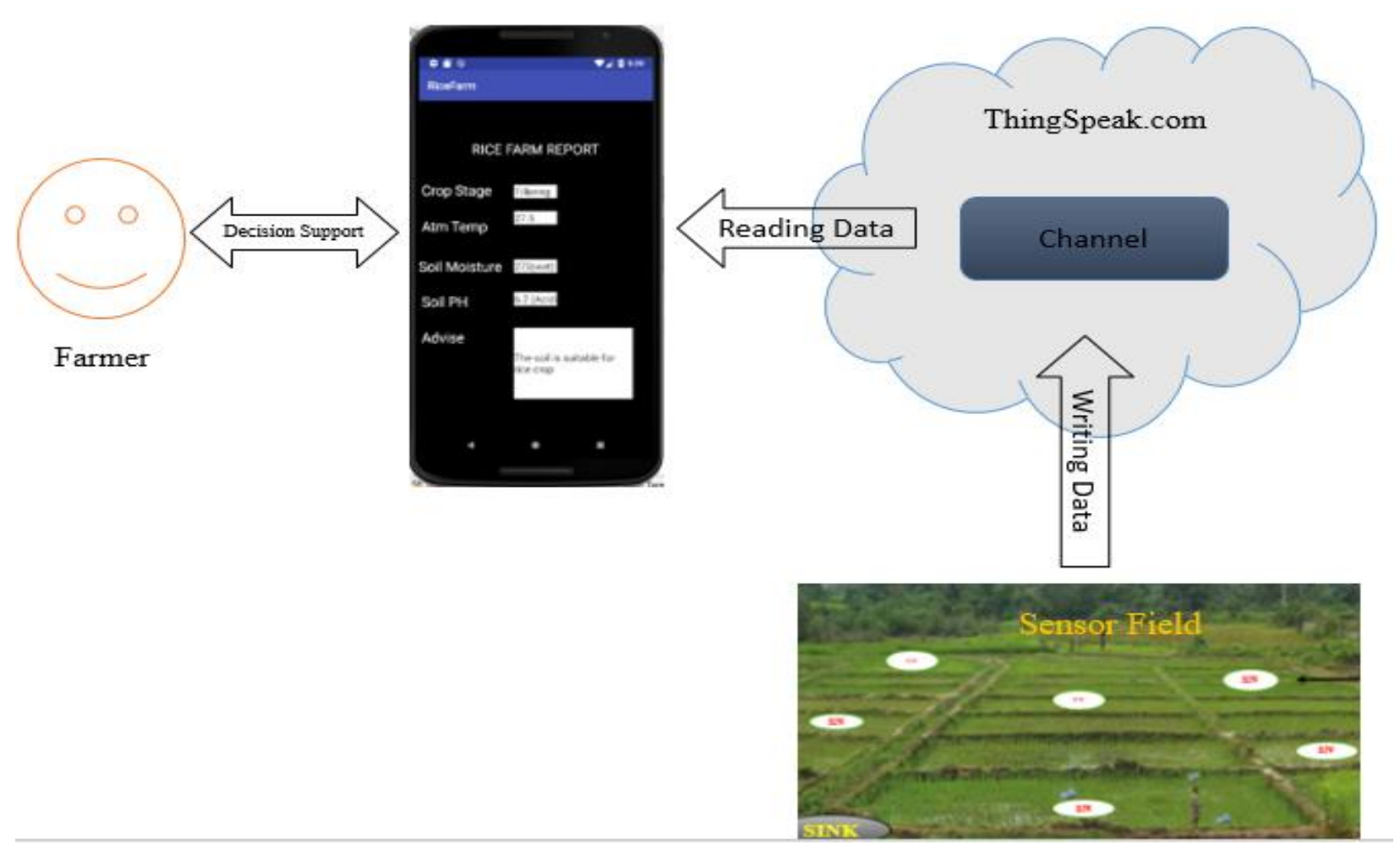

Figure 10. Decision Support System App Architectural Diagram

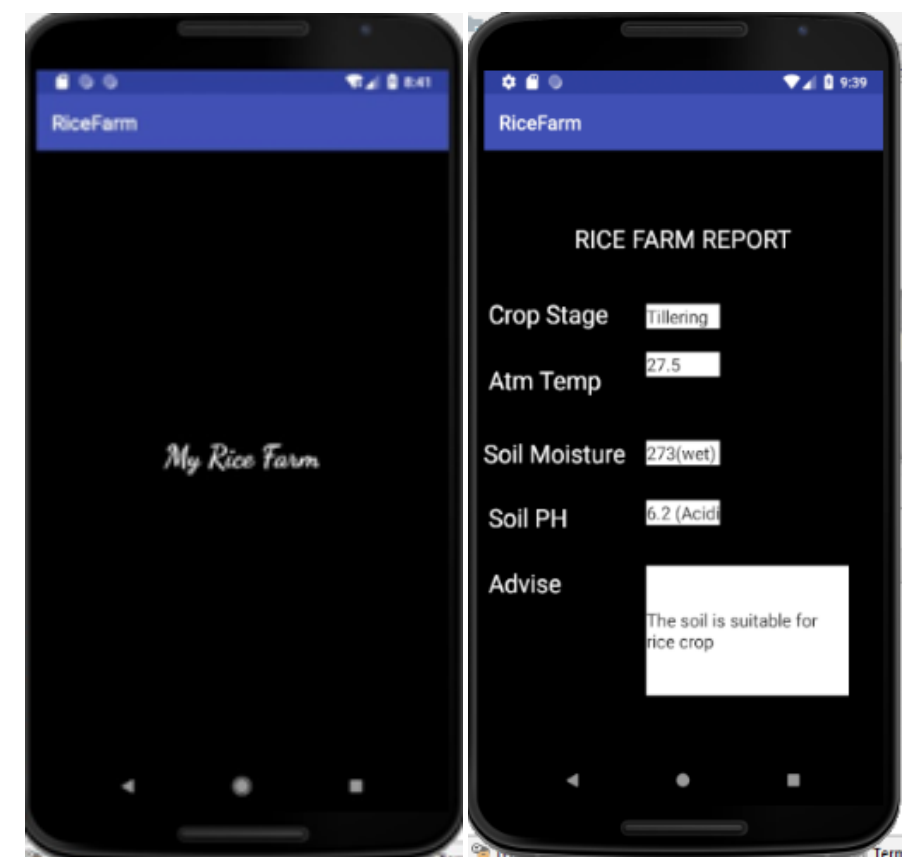

Figure 11. Farmer App for Decision Support

\section{Conclusion}

Information Technology (IT) has become a substantial instrument for gaining competitive advantage in the corporate and social world, and several school of thought had suggested that the recent increase in economic productivity in Nigeria had been possible due to efficient communication, facilitated by increased access to telephone and the Internet. Thus the growth of agricultural sector can be improved by tapping into this opportunity. 
This study had presented several tool capable of providing information to farmers about their farm in order to improve the yield of the cultivated crops. A decision support system using mobile App for rice farmers was developed.

\section{References}

[1] Merriam Webster. (2018); Available from: https://www.merriam-webster.com.

[2] Pongnumkul, S., Chaovalit, P. and Surasvadi, N. (2015) "Applications of smartphone-based sensors in agriculture: a systematic review of research", Journal of Sensors, Volume 2015, p. 1-18, http://dx.doi.org/10.1155/2015/195308

[3] Lasanthi N.C., Goonetillake J. S., Wikramanayake G. N., and Ginige A. (2013) "Farmer response towards the initial agriculture information dissemination mobile prototype" International Conference on Computational Science and Its Applications. Springer.

[4] Jumia (2017), "Nigeria Mobile Trends".

[5] Central Intelligence Agency (CIA). (2018) "The World FactBook. 2018" Available from: https://www.cia.gov/library/publications/the-world-factbook/geos/ni.html.

[6] Adekunle, O.A., Adefalu, L. L., Oladipo F. O., Adisa R. S., Fatoye A. D., (2009) "Constraints to youths' involvement in agricultural production in Kwara State, Nigeria." Journal of agricultural extension, 13(1).

[7] Singhal, M., Verma, K. and Shukla, A. (2011), "Android based solution for Indian agriculture", IEEE 5th International Conference on Advanced Networks and Telecommunication Systems (ANTS),

[8] Trimble. Connected Farm Field. 2017 [cited 2018 13th August]; Available from: https://agdeveloper.trimble.com/project/connected-farm-field/.

[9] Oklahoma-State-University (2018) "Canopeo" Available from https://appcenter.okstate.edu/content/canopeo.

[10] "Make Farm Management Easier." (2015); Available from: https://www.farmathand.com/.

[11] "PotashCorp eKonomics Introduces Updated ROI Calculator." (2016) Available from: https://www.croplife.com/crop-inputs/potashcorp-ekonomics-introduces-updated-roi-calculator/.

[12] "Farmer's Toolbox ImagelT" (2018) Available from: https://www.yara.co.uk/crop-nutrition/farmerstoolbox/imageit/.

[13] "Your premier agriculture platform for real-time agronomy and sustainability with a global reach" (2018) Available from: https://www.agrible.com/\#mobileapps.

[14] AfricaRice (2018) "AfricaRice launches free mobile app for rice weed control in Africa"

[15] Seck, P.A., Diagne, A., Mohanty, S. and Wopereis, M.C.S. (2012) "Crops that feed the world 7: Rice. Food Security". 4(1): p. 7-24.

[16] Food and Agricultural Organisation Yearbook (2013) "World food and agriculture" Food and Agriculture Organization of the United Nations, Rome, p. 15.

[17] Lee, T. R., (2000) "The Application of Decision Support System to Forecast the Yield of Agricultural Products in Taiwan." p. 8.

[18] Durakovic, B., (2017) "Design of Experiments Application, Concepts, Example: State of the Art." Periodicals of Engineering and Natural Sciences, 5(3): p. 421-439.

[19] Ghadirnezhad, R. and Fallah, A., (2014) "Temperature effect on yield and yield components of different rice cultivars in flowering stage. International Journal of Agronomy.

[20] Momolu, E.P., Katuromunda, S. and Lamo, J. (2016) "Effect of Soil Moisture Stress Duration on the Growth Characteristics and Yield of Rice Cultivars. From http://ir.bsu.ac.ug/xmlui/handle/20.500.12284/143 
[21] Kobayashi O., Higuchi K., Miwa E., and Tadano T., (2010) "Growth injury induced by high pH in rice and tomato. Soil Science \& Plant Nutrition" 56(3): p. 407-411.

[22] International Rice Research Institute (IRRI) (2018) "Rice Knowledge Bank: Your Information Source for Rice Farming" Available from: www.knowledgebank.irri.org/step-by-stepproduction/growth/pests-and-diseases.

[23] Saračević, M.H., A. Selimi, and M. Mujevic, (2018) "Implementation Example of the Expert system for Decision Support on Android platform based on a specific Dataset". Periodicals of Engineering and Natural Sciences (PEN), 6(1): p. 76-83. 